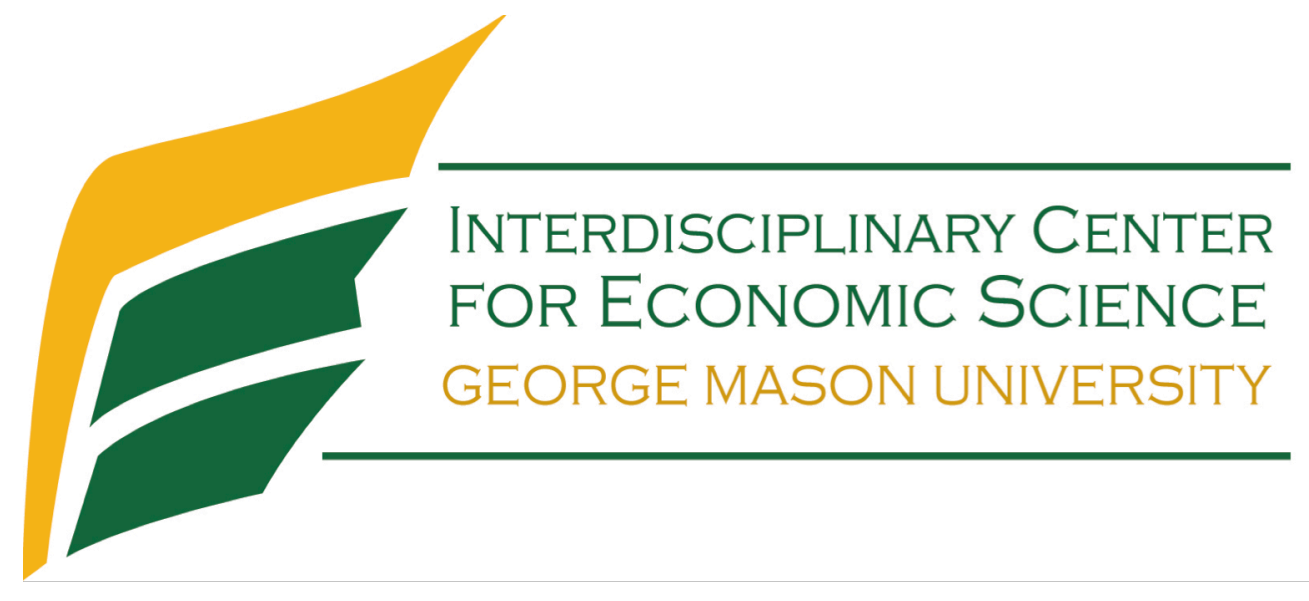

\title{
Political Economics of Broadcast Media
}

\author{
Alejandro Castañeda and César Martinelli
}

September 2015

Discussion Paper

Interdisciplinary Center for Economic Science

4400 University Drive, MSN 1B2, Fairfax, VA 22030

Tel: +1-703-993-4719 Fax: +1-703-993-4851

ICES Website: $h$ ttp://ices.gmu.edu

ICES RePEc Archive Online at: http://edirc.repec.org/data/icgmuus.html 


\title{
Political Economics of Broadcast Media
}

\author{
Alejandro Castañeda César Martinelli *
}

September 3, 2015

\begin{abstract}
We offer a tractable model of broadcast media as a three-sided platform, serving entertainment and news to viewers, commercial opportunities to advertisers, and electoral influence to politicians. We characterize the profitmaximization decision of a media firm, and study the effect on social welfare of changes in the value of electoral influence, via induced changes in commercial advertising, the entertainment value of media, and political distortions.
\end{abstract}

\section{Introduction}

Through a purely economic lens, mass media firms can be conceptualized as twosided platforms. On the one hand, they provide a flow of entertainment and news to viewers or readers, often at prices that are subsidized by other activities, or even for free, as in the case of broadcast TV. On the other hand, media firms provide, at a price, a platform for advertisers, thereby contributing to create trade opportunities. Because of their role as purveyors of news and commentary, media firms are also bound to have an important influence on public opinion and political behavior. This influence creates the opportunity, and the temptation, for a different type of transaction, namely a mutually advantageous relationship with politicians, in which media use their clout to favor particular politicians or parties in exchange for favorable regulation to media or their business partners, over or under the table payments, and other forms of direct or indirect compensation. Peddling political

\footnotetext{
*Castañeda: Colegio de México. Email: acasta@colmex.mx. Martinelli: Interdisciplinary Center for Economic Science and Department of Economics, George Mason University. Email: cmarti33egmu. edu. We thank David Levine and audiences at the 2015 Priorat Workshop in Theoretical Political Science and the Catholic University of Peru for comments and suggestions, and the organizers of the Priorat workshop, Enriqueta Aragones, Tom Palfrey, Andrea Mattozzi, and John Patty, for their kind invitation.
} 
influence, of course, is not costless for a media firm-at the margin, it may detract from the entertainment value of the firm, lead to a loss of audience, and detract from commercial revenue.

In this paper, we study the problem of a profit-maximizing media firm which exploits its political influence as a three-sided platform. As in the case of broadcast TV, we assume that the firm provides entertainment for free to viewers. The size of the audience, that is the reach of the media firm among the citizenry, is determined by the nuisance created by commercial advertising and political peddling. Crucially in terms of political implications of the model, citizens' tolerance to nuisance is negatively correlated with wealth, so that viewership is concentrated among the poorer citizens. The media firm also provides, at a price, space to advertisers, who can appropriate the gains from trade opportunities with viewers. Potential advertisers differ in terms of the quality of their trade opportunities, so that for any given price set by the firm for commercial ads, the marginal advertiser is given by the quality of her trade opportunity and the reach of the media. Finally, we assume that the media firm exploits its political clout by setting up an auction among competing politicians. The amount of peddling by the firm is a choice variable, contributing to increase the value of the auction of the firm's favors among politicians, but reducing the firm's audience and thereby other sources of revenue.

Treatment of politics in the model is highly stylized. There are two competing politicians who are vote-maximizers, and who compete in an election by offering policies on the real line. Citizens have heterogeneous policy preferences, with poorer citizens having larger ideal policy positions. We can think of public policy as consisting of setting the level of public spending, of which poorer citizens may benefit more. Citizens who are active viewers may be influenced by the media firm to vote for the politician favored by the firm, regardless of their policy interests, introducing a possible gap between the median preferences of citizens and the effective median voter. Thus, by virtue of the fact that poorer citizens are a large fraction of the media audience, single-minded profit maximization by the media firm may end up provoking political distortions, even if neither the firm nor the politicians have policy preferences.

In this context, we study the effect of variations in the political rents accruing to politicians on the firm decisions, via the increased willingness of politicians to pay for political peddling by the firm. We show that, as long as the influence of media on active viewers is not complete, so that additional political peddling can influence active viewers at the margin, an increase in political rents reduces commercial advertisement, strictly increases political peddling, and strictly reduces the size of the audience for the media. When the influence of media on viewers is complete, so that the media firm hits a corner in terms of intramarginal political influence, the implications of changes in political rents are partially reversed-an 
increase in political rents reduces commercial advertising but it also increases the audience for the media. Intuitively, the media firm reacts now to the increased willingness to pay for votes by attempting to increase the size of the audience. We also show that, as long as the effective median voter is an active viewer, an increase in political rents results in larger political distortions.

We then take a look at the welfare implications of changes in political rents. To this effect, we decompose the impact of media on welfare into three components, the effect of media on viewers' entertainment, the effect of media on trade opportunities (which in our model are reaped by advertisers), and the effect of media on the political process. We show that, if the influence of media on voters is not complete, and the effective median voter is a viewer, there is an unambiguously negative effect of political rents on social welfare. This is because larger political rents affect negatively all three components.

Last, we consider the optimal regulation of the firm's activities. We show that, if the regulator can determine the firm's choices, a positive level of political peddling is never optimal. If, as it may perhaps strike as more realistic, the regulator can affect influence peddling, but cannot determine the firm's commercial decisions, then the conclusion is more nuanced. Shutting down political peddling is indeed beneficial from the viewpoint of social welfare if, in the absence of regulation, profit maximization leads the firm to choose only partial political influence. If political rents are high enough so that profit maximization leads the firm to choose complete political influence, society may be worse off banning political peddling. Intuitively, in this case the effects of media decisions, as induced by the possibility of selling political influence, on the commercial and the entertainment value of the media are in conflict. Selling political influence crowds out commercial advertising, but also provides incentives for the firm to reach for a larger audience.

Some of the forces at work in the model are illustrated by the case of Mexico. In Mexico ownership of broadcast TV stations is concentrated in two giant conglomerates. A recent study (Telecom-CIDE, 2011) shows that $48 \%$ of geographical concessions are owned by Televisa, and a further $7 \%$ are owned by its affiliated stations. TV Azteca (the second major broadcaster) owns $39 \%$ of geographical concessions. Televisa owns three channels with national coverage, and TV Azteca owns two; there is no other firm with national coverage. Recently, two national chains were put on for auction by IFT (Federal Institute for Telecommunications). However, only one concession was allocated. The electoral influence of Mexican's giant broadcast conglomerates in the 2000 presidential elections is discussed, for instance, by McCann and Lawson (2005). In a seemingly exchange, media regulation has tended to favor the conglomerates. At the end of 2005 and in March 2006, a law on broadcast TV was approved by both chambers of the Mexican legislative. The law establishes asymmetric regulation between incum- 
bents and new entrants (in favor of incumbents), and the possibility of concession of highly valued spectrum for free for the incumbents. The passage in the lower chamber was unanimous, taking all of seven minutes-a record speed. Only a few Senate members dare to oppose the law, to no avail, with the 2006 federal elections possibly looming in the minds of legislators. In congruence with the assumption of the model, TV watching in Mexico is concentrated in the lower socioeconomic levels, with the most watched programs being news and soap operas (IBOPE AGB, 2009).

Evidence of monetary payments from politicians to media, out of legal campaign advertising, since outright payments in exchange for biased reporting and opinion pieces may be illicit. Some unusual evidence from Fujimori's regime in Peru is provided by Mcmillan and Zoido (2004). Though Fujimori's presidency exhibited some authoritarian characteristics, it relay on electoral support, and control of media and especially broadcast TV was considered key in this respect by the government, as evidenced by the size of the bribes rendered to TV owners.

The relationship between that entertainment value and the political interests of the media is, of course, complex; recent political commentary on the treatment of Trump's US presidential campaign by Fox News hints at the conflicting objectives of the media conglomerate. Klein (2015), for instance, quotes conservative commentator David Frum, "Republicans originally thought that Fox worked for us, and now we're discovering we work for Fox."

There is a burgeoning literature on the political economy of media. The literature has moved from assessing the evidence of bias (Groseclose and Milyo, 2005), to estimating the electoral impact of media conglomerates' bias (DellaVigna and Kaplan, 2007; Gentzkow et al., 2011), to discussing the sources of bias in either reputational incentives and other supply sources (Gentzkow and Shapiro, 2006) or in cognitive limitations of readers and viewers and other demand sources (Duggan and Martinelli, 2011; Mullainathan and Shleifer, 2005) or in both supply and demand factors (Bernhardt et al., 2008), to discussing the importance of media for the control of incumbent politicians (Besley and Prat, 2006). The literature is summarized from different perspectives by Prat and Stromberg (2013) and Gentzkow and Shapiro (2015).

Two sided-markets are the object of attention of a growing body of research in industrial organization, including the influential contributions of Armstrong (2006), Rochet and Tirole (2003), and Weyl (2010). This literature has focused on the existence of externalities in which agents in one side of the market benefit from the participation of agents or the transactions conducted by agents on the other side of the market. Closer to our work is the model of broadcast media offered by Anderson and Coate (2005); as in their work, we assume that viewers or readers are fully subsidized by other sides of the market, and that advertisers appropriate the 
rents created by trade opportunities. We extend their framework to include politics as another side of the media activities and transactions. From a wider perspective, we aim at tending a bridge between the political economy and the industrial organization literatures on media; we believe a proper study of regulatory issues, as exemplified recently by Prat (2014), needs to integrate both perspectives.

The remainder of this paper is organized as follows. In Section 2 we present a political economic model of a dominant media firm. In section 3 we characterize the profit-maximizing behavior of the media firm. In section 4 we study the comparative statics implications of changes in political rents on commercial advertising and political outcomes. In section 5 we discuss the regulation of political influence. Section 6 gathers concluding remarks.

\section{The model}

\subsection{Citizens, politicians, and media}

The agents in the model are a continuum of citizens, two politicians, and a single media firm. A fraction $V \in(1 / 2,0)$ of citizens are (potential) viewers, while the remainder are (potential) advertisers.

Each citizen has an idiosyncratic endowment of two consumption goods, good 1 (the numeraire) and good 2. The two consumption goods are perfect substitutes for viewers but advertisers can only consume good 1, so there are potential benefits from trade. Trade is decentralized, as described below. The two politicians, $i=1,2$, compete in an election to provide a public good on which citizens have heterogeneous preferences.

The media firm facilitates trade between viewers and advertisers, and votegetting by politicians, acting as a monopoly in a three-sided market (see Figure 1). In particular, the media firm: (i) offers entertainment for free to viewers, (ii) sets a price $p$ for commercial ads, which are offered to advertisers, and (iii) sets a political ad space $a_{e}$ and auctions it off between the two politicians in a first price auction. ${ }^{1}$ Both the price for commercial ads and the bids for political ad space are set in units of good 1 .

The total ad space sold by the firm, $a$, is equal to the sum of the mass of advertisers who buy commercial ads, $a_{c}$, and the political ad space, $a_{e}$. The firm's

\footnotetext{
${ }^{1}$ We assume a first price auction for simplicity but the actual format of the auction is not important-since the value of the political space for politicians is common knowledge, and is the same for both politicians, a second price auction or simply a posted price would lead to the same results.
} 


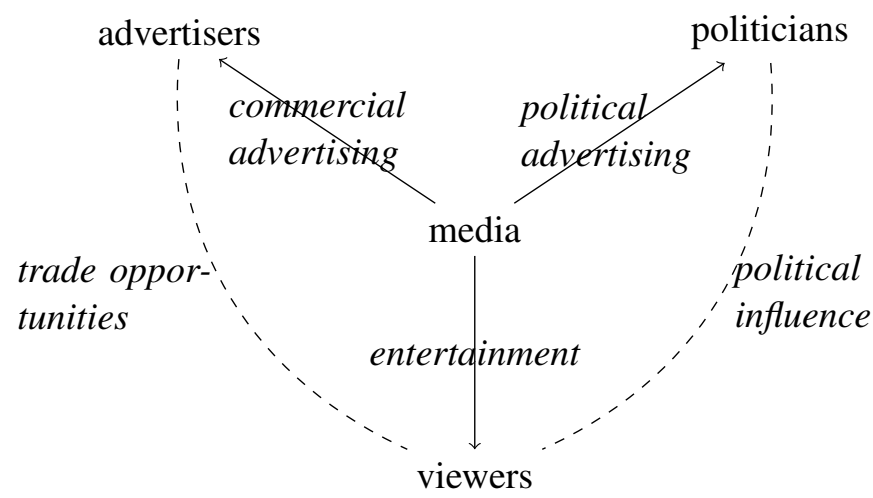

Figure 1: Media as a three-sided market

operating cost is zero, so the firm's payoff is given by its revenue,

$$
p a_{c}+\max _{i} b_{i}
$$

where $b_{i}$ is the bid submitted by politician $i$. Note that we treat differently the market for commercial advertisement, where the media firm faces a large number of small players, from the market for political influence, where all participants are large players.

Watching the media provides viewers with a payoff that is decreasing in the total ad space sold by the media firm (because of the nuisance aspect of advertising and peddling) and in their consumption of goods 1 and 2 (because media watching is assumed to be an inferior good). In particular, if the total ad space sold is $a \in$ $[0,1]$, then a viewer's payoff from watching the media, which may be positive or negative, is

$$
w\left(c_{1}, c_{2}, a\right)=1-\lambda\left(c_{1}+c_{2}\right)-\gamma a,
$$

where $c_{1}$ and $c_{2}$ represent consumption levels of good 1 and $\operatorname{good} 2$, and $0<\lambda \leqslant$ $1 / 2$ and $\gamma>0$ are preference parameters. ${ }^{2}$

Trade between a viewer and an advertiser can only happen if the viewer watches the media, that is, if the viewer becomes an active viewer, and the advertiser posts an ad with the media firm, that is, if the advertiser becomes an active advertiser. If the fraction of viewers who are active is $v$, then the probability that an active

\footnotetext{
${ }^{2}$ Our assumption about media's entertainment value being larger for poorer consumers is consistent with the evidence about the number of hours spent watching TV being negatively correlated with income; see e.g. Dooe (2013), who uses US data from the General Social Survey (NORC, 2014), and the evidence on Mexico mentioned above.
} 
advertiser meets a viewer is $v \sigma$, where $\sigma$ is an idiosyncratic parameter representing the quality of the advertiser. That is, the effectiveness of posting an add depends on the audience of the media and on idiosyncratic characteristics of the advertiser. If an advertiser meets a viewer, the advertiser gets to make a take-it-or-leave it offer to the viewer, containing a proposed exchange of units of good 2 owned by the advertiser for units of good 1 held by the viewer. That is, the advertiser appropriates the whole surplus generated by a meeting. (This implies that the only value of watching the news is the entertainment value).

Politicians compete by committing simultaneously to levels of provision of the public good. The winner of the election is the politician who obtains most votes, with ties broken randomly. During the election, a fraction of active viewers are swayed to vote for the politician who wins the auction of political ad space. In particular, if the media firm auctions off ad space equal to $a_{e}$, a fraction $\min \left\{\delta a_{e}, 1\right\}$ of active viewers vote for the winner of the auction independently of the politicians' proposals. That is, a fraction of active viewers just vote for the media winner, and the rest vote based on preferences. The parameter $\delta>0$ measures the political influence of media. We refer to citizens who are swayed by political ads as influenced voters. Politicians payoffs are given by their electoral reward, which is equal to their share of votes in the election times $r$, where $r>0$, minus the bid for the auction winner.

Preferences of citizens over the level of the public good are Euclidean, with favorite points given by $X\left(c_{1}+c_{2}\right) \equiv \alpha-\beta\left(c_{1}+c_{2}\right)$ for viewers and $X\left(c_{1}\right)$ for advertisers, where $\alpha \in \mathfrak{R}$ and $0<\beta<1 / 2$. That is, the public good is an inferior good.

Payoffs to viewers and advertisers are given, respectively, by

$$
c_{1}+c_{2}-\left|x-X\left(c_{1}+c_{2}\right)\right|+\mathfrak{t} w\left(c_{1}+c_{2}, a\right)
$$

and

$$
c_{1}-\left|x-X\left(c_{1}\right)\right|,
$$

where $x \in \Re$ is the level of the public good chosen by the election winner, and $\mathbf{l}$ is an indicator function that takes the value 1 if the viewer is active and 0 otherwise.

We assume that viewers' endowment of good 1 is distributed according to to a distribution function $F$ satisfying $F\left(\underline{\omega}_{1}\right)=0, F\left(\bar{\omega}_{1}\right)=1$, and $F\left(\omega_{1}\right)$ strictly increasing and continuously differentiable over the interval $\left(\underline{\omega}_{1}, \bar{\omega}_{1}\right)$, where $0<\underline{\omega}_{1}<$ $\bar{\omega}_{1}$ and $\underline{\omega}_{1}<1 / \lambda$; the last inequality implies that some viewers become active if advertisement is small enough. Viewers endowment of good 2 is 0 . Advertisers' endowment of good 1 and good 2 are, respectively $\bar{\omega}_{1}$ and $\bar{\omega}_{2}$, where $\bar{\omega}_{2}>0$. Moreover,

$$
\bar{\omega}_{2} \leqslant \underline{\omega}_{1} .
$$


This inequality guarantees that, conditional upon meeting an active viewer, the advertiser can offer the viewer $\bar{\omega}_{2}$ units of good 2 in exchange for $\bar{\omega}_{2}$ units of good 1. This is not an innocuous assumption; it implies that advertisers do not prefer to meet richer viewers (i.e. those viewers with a larger endowment of good 1).

We assume that the quality of the advertiser and is distributed over advertisers according to a distribution function $G$ satisfying $G(0)=0, G(1)=1$, and $G(\sigma)$ strictly increasing and continuously differentiable over the interval $(0,1)$.

We also assume that

$$
F \text { is log-concave over }\left(\underline{\omega}_{1}, \bar{\omega}_{1}\right) \text {, and } G \text { is convex over }(0,1) \text {. }
$$

This guarantees that the equilibrium path of the model is unique. An example is $F$ being a uniform distribution over the interval $\left[\underline{\omega}_{1}, \bar{\omega}_{1}\right]$, and $G$ a standard uniform distribution; more generally examples can be constructed using Beta distributions for both $F$ and $G$. Log concavity of $F$ is reasonable as a representation of a declining density of the distribution of wealth; convexity of $G$ implies convexity of the demand function for commercial advertisement holding active viewership constant.

To guarantee that ex post consumption levels are positive for all agents, we can assume that an active advertiser's payment to the media firm is conditional to their meeting a viewer, and is equal to $p_{c}$ in expected terms. The price of commercial ads can be capped at $\bar{\omega}_{1}$; this bound is not binding in equilibrium. We can also assume that politicians have "deep pockets" in the sense of an initial endowment of good 1 and can pay the firm up to $r$ units of good 1 .

\subsection{Strategies and equilibrium}

The media firm, politicians and citizens play a multistage game, as outlined in Figure 2. In the first stage of the game, the media firm sets a price $p$ for commercial ad space, and a political ad space $a_{e}$ to be auctioned. In the ad markets stage, advertisers decide whether or not to buy commercial advertising space, while politicians bid for the political ad space. In the viewership stage, viewers decide whether to watch or not the media. In the electoral competition stage, the two politicians propose simultaneously levels of the public good to citizens. In the voting stage, uninfluenced voters decide whom of the two politicians to vote for, while influenced voters vote for the politician who won the political ad space auction. After voting, nature matches randomly some active advertisers to some active viewers. In the trading stage, active advertisers who have met viewers make an exchange proposal. Afterwards, viewers accept or reject those proposals. Consumption takes place, and payoffs are realized. 


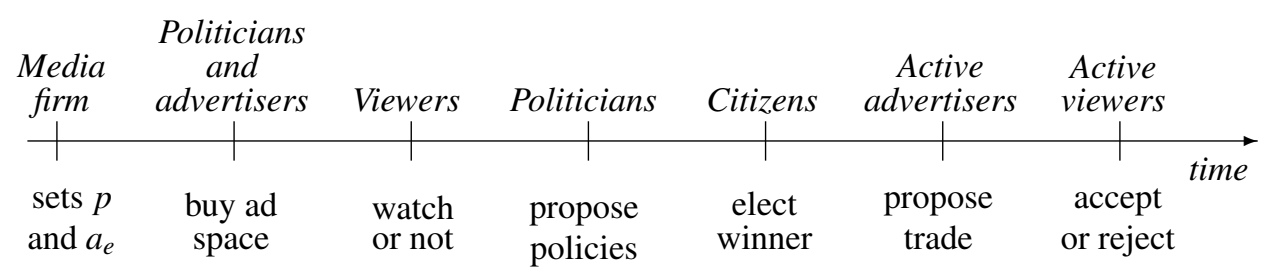

Figure 2: Timeline

We proceed to define formally histories, strategies and equilibrium for the game. We denote by $\Omega$ the set of measurable subsets of the set $\left[\underline{\omega}_{1}, \bar{\omega}_{1}\right]$ and by $\Sigma$ the set of measurable subsets of the set $[0,1]$. A history at the ad market stage is a pair in $\mathcal{H}_{a} \equiv \mathfrak{R}_{+}^{2}$ specifying the media firm choice of commercial price and political ad space in the previous stage. A history at the viewership stage is an element of $\mathcal{H}_{w} \equiv \mathcal{H}_{a} \times \mathfrak{R}_{+}^{2} \times\{1,2\} \times \Sigma$ specifying the history in the previous stage as well as the bids submitted by politicians and the winner of the auction (which is decided by nature in case of equal bids) and the subset of active advertisers. A history at the electoral competition stage is an element of $\mathcal{H}_{e} \equiv \mathcal{H}_{v} \times \Omega$ specifying the history in the previous stage as well as the subset of active viewers. A history at the voting stage is an element of $\mathcal{H}_{v} \equiv \mathcal{H}_{e} \times \mathfrak{R}_{+}^{2}$ specifying the history in the previous stage as well as the public good levels proposed by the two politicians. A history at the trading stage is an element of $\mathcal{H}_{t} \equiv \mathcal{H}_{v} \times\{1,2\}$ specifying the history in the previous stage as well as the winner of the election (which is decided by nature in case of a tie in the election). A personal history for an active viewer at the last stage specifies the history in the previous stage as well as the offer received by the viewer, which is a proposed trade of $x \in\left[0, \underline{\omega}_{1}\right]$ units of good 1 held be the viewer for $y \in\left[0, \bar{\omega}_{2}\right]$ units of good 2 held be the advertiser. ${ }^{3}$

A strategy for the media firm is a pair $\left(p, a_{e}\right) \in \mathfrak{R}_{+}^{2}$. A strategy for each politician $i$ is a pair of measurable functions, $\mathcal{P}_{i}^{a}, \mathcal{P}_{i}^{e}$, where

$$
P_{a}^{i}: \mathcal{H}_{a} \rightarrow \Re_{+} \quad \text { and } \quad P_{e}^{i}: \mathcal{H}_{e} \rightarrow \Re_{+}
$$

specify, respectively a bid at the ad market stage and a level the public good at the electoral competition stage, as a function of previous history.

\footnotetext{
${ }^{3}$ For simplicity, we do not keep track of the votes of different citizens, and only of the result of the election. Also for simplicity, we do not keep track of the identity of the viewer in a matched pair, and restrict proposed trades to be such that they are feasible for any matched pair. This constraint is not binding in equilibrium under assumption $\mathrm{A}$.
} 
A strategy for viewers is a triple of measurable functions, $\mathcal{V}_{w}, \mathcal{V}_{v}, \mathcal{V}_{l}$, where

$$
\mathcal{V}_{w}: \mathcal{H}_{t} \times\left[\underline{\omega}_{1}, \bar{\omega}_{1}\right] \rightarrow\{\text { active, inactive }\} \quad \text { and } \quad \mathcal{V}_{v}: \mathcal{H}_{v} \times\left[\underline{\omega}_{1}, \bar{\omega}_{1}\right] \rightarrow\{1,2\}
$$

specify, respectively, whether the viewer becomes active or not, and whether the viewer supports politician 1 or 2 , as a function of previous history and the endowment of the viewer, and

$$
\mathcal{V}_{l}: \mathcal{H}_{l} \times\left[0, \underline{\omega}_{1}\right] \times\left[0, \bar{\omega}_{2}\right] \times\left[\underline{\omega}_{1}, \bar{\omega}_{1}\right] \rightarrow\{\text { accept, reject }\}
$$

specifies whether the viewer accepts or rejects the trade proposed, in case of becoming active and being matched, as a function of personal history (including the trade proposed) and the the endowment of the viewer.

Finally, a strategy for advertisers is a triple of measurable functions, $\mathcal{A}_{a}, \mathcal{A}_{v}, \mathcal{A}_{t}$, where

$$
\mathcal{A}_{a}: \mathcal{H}_{t} \times[0, \bar{\sigma}] \rightarrow\{\text { active, inactive }\} \quad \text { and } \quad \mathcal{A}_{v}: \mathcal{H}_{v} \times[0, \bar{\sigma}] \rightarrow\{1,2\}
$$

specify, respectively, whether the advertiser becomes active or not, and whether the advertiser supports candidate 1 or 2 , as a function of previous history and the quality of the advertiser, and

$$
\mathcal{A}_{t}: \mathcal{H}_{l} \times[0, \bar{\sigma}] \rightarrow\left[0, \underline{\omega}_{1}\right] \times\left[0, \bar{\omega}_{2}\right]
$$

specifies the trade proposed by the advertiser, in case of becoming active and being matched, as a function of previous history and the quality of the advertiser.

Subgame perfect equilibrium for this game is a profile of strategies that induces a Nash equilibrium at every subgame of the game-that is at every stage, after every possible previous history, players play best responses to other players' actions. Note that at the voting stage, best response behavior does not impose any constraint on the behavior of citizens-since there is a continuum of them, a single citizen is never decisive. As customary in modeling two candidate elections with a continuum of voters, we impose that citizens (who are not influenced) (i) vote for the politician whose policy they prefer, and (ii) split their votes exactly between the two candidates in case of indifference. We refer to a subgame perfect equilibrium satisfying (i) and (ii) as a political economic equilibrium.

\section{Political economic equilibrium}

In this section, we study the equilibrium of the model described in the previous section. Let define first

$$
P\left(a_{c}, a_{e}\right) \equiv \bar{\omega}_{2} G^{-1}\left(1-a_{c}\right) F\left(\left(1-\gamma\left(a_{e}+a_{c}\right)\right) / \lambda\right) .
$$


As we will see, $P\left(a_{c}, a_{e}\right)$ is the inverse demand function for commercial advertising; it tells us what is the price that the media firm needs to charge if the firm targets a level of commercial advertising equal to $a_{c}$, given that the firm has chosen a political ad space equal to $a_{e}$. From assumption $\mathrm{B}$, the indirect demand $P$ is $\log$ concave, and the indirect demand per viewer, $\bar{\omega}_{2} G^{-1}\left(1-a_{c}\right)$, is concave.

To provide an intuition for $P$, observe that if viewers anticipate advertisers to appropriate all gains from trade, the marginal active viewer is given by $w\left(\omega_{1}, 0, a\right)=$ 0 or equivalently $\omega_{1}=(1-\gamma a) / \lambda$, so that the fraction of active viewers is $F((1-$ $\gamma a) / \lambda) . P$ is then equal to the gain from posting an ad, $\sigma \bar{\omega}_{2} F((1-\gamma a) / \lambda)$, for the marginal active advertiser, whose quality is $\sigma=G^{-1}\left(1-a_{c}\right)$, given correct expectations about viewers' decisions. It turns out that in formulating the problem of the media firm is simpler to work with the inverse demand function, presenting the firm as choosing $a_{e}$ and, indirectly, $a_{c}$.

Let

$$
\pi\left(a_{c}\right) \equiv a_{c} G^{-1}\left(1-a_{c}\right)
$$

for $0 \leqslant a_{c} \leqslant 1$. Intuitively, $\bar{\omega}_{2} \pi\left(a_{c}\right)$ is the revenue per viewer $a_{c} P\left(a_{c}, a_{e}\right) / F((1-$ $\gamma a) / \lambda$ ) obtained by selling commercial advertisement. From assumption $\mathrm{B}, \pi$ is a strictly concave function, with $\pi^{\prime}(0)=1$ and $\pi^{\prime}(1)=-1$.

Let define also

$$
C\left(a_{c}, a_{e}\right) \equiv 1-\min \left\{\delta a_{e}, 1\right\} V F\left(\left(1-\gamma\left(a_{c}+a_{e}\right)\right) / \lambda\right)
$$

and

$$
\begin{aligned}
& H\left(x \mid a_{c}, a_{e}\right) \equiv \\
& \int \frac{1-V}{C\left(a_{c}, a_{e}\right)}\left(1-G\left(\frac{X^{-1}(x)-\bar{\omega}_{1}+P\left(a_{c}, a_{e}\right)}{\bar{\omega}_{2} F\left(\left(1-\gamma\left(a_{c}+a_{e}\right)\right) / \lambda\right)}\right)\right) \\
& \text { if } X\left(\bar{\omega}_{1}+\bar{\omega}_{2} F\left(\left(1-\gamma\left(a_{c}+a_{e}\right)\right) / \lambda\right)-P\left(a_{c}, a_{e}\right)\right) \leqslant x<X\left(\bar{\omega}_{1}\right) \text {, } \\
& \frac{1-V F\left(X^{-1}(x)\right)}{C\left(a_{c}, a_{e}\right)} \quad \text { if } X\left(\bar{\omega}_{1}\right) \leqslant x \leqslant X\left(\left(1-\gamma\left(a_{c}+a_{e}\right)\right) / \lambda\right) \\
& 1-\frac{\left(1-\min \left\{\delta a_{e}, 1\right\}\right) V F\left(X^{-1}(x)\right)}{C\left(a_{c}, a_{e}\right)} \quad \text { if } X\left(\left(1-\gamma\left(a_{c}+a_{e}\right)\right) / \lambda\right) \leqslant x \leqslant X\left(\underline{\omega}_{1}\right) .
\end{aligned}
$$

As we will see, $C\left(a_{c}, a_{e}\right)$ and $H\left(x \mid a_{c}, a_{e}\right)$ are, respectively, the mass of voters who are not influenced and the distribution of their ideal points regarding public good provision, along the equilibrium path of play in the ensuing subgame after the firm chooses $a_{e}$ and $p$ satisfying $p=P\left(a_{c}, a_{e}\right)$. 
The first line of the definition of $H$ corresponds to the ideal points of active advertisers, the second line corresponds to the ideal points for inactive viewers, and the third line corresponds to the ideal points of active viewers who are not influenced. The distribution $H$ is discontinuous at $X\left(\bar{\omega}_{1}\right)$; this is because the ideal points of inactive advertisers pool at $X\left(\bar{\omega}_{1}\right)$. To see this, note that

$$
\lim _{x \uparrow X\left(\bar{\omega}_{1}\right)} H\left(x \mid a_{c}, a_{e}\right)=\frac{(1-V) a_{c}}{C\left(a_{c}, a_{e}\right)},
$$

which is the fraction of uninfluenced voters who are active advertisers, but

$$
H\left(X\left(\bar{\omega}_{1}\right) \mid a_{c}, a_{e}\right)=\frac{1-V}{C\left(a_{c}, a_{e}\right)},
$$

which is the fraction of uninfluenced voters who are advertisers.

Note that the distribution function $H\left(x \mid a_{c}, a_{e}\right)$ has a compact support, so it has a unique median given by $H\left(x \mid a_{c}, a_{e}\right)=1 / 2$.

We have

Theorem 3.1. (i) There exists a political economic equilibrium, and the equilibrium path is unique. (ii) In the political economic equilibrium, the media firm sets the political ad space at $a_{e}^{*}$ and the price for commercial ads at $p^{*}=P\left(a_{c}^{*}, a_{e}^{*}\right)$, where $a_{c}^{*}$ and $a_{e}^{*}$ solve

$$
\max _{\substack{a_{c} \geqslant 0 \\ 0 \leqslant a_{e} \leqslant 1 / \delta}}\left\{\left(\bar{\omega}_{2} \pi\left(a_{c}\right)+\delta r a_{e}\right) \times F\left(\left(1-\gamma\left(a_{c}+a_{e}\right)\right) / \lambda\right)\right\}
$$

(iii) Suppose the media firm chooses $a_{e}$ and $p>0$, and let $a_{c}$ be given implicitly by $p=P\left(a_{c}, a_{e}\right)$. Along the equilibrium path in the ensuing subgame, both politicians bid $\delta r a_{e} F\left(\left(1-\gamma\left(a_{c}+a_{e}\right)\right) / \lambda\right)$, advertisers become active if $\sigma \geqslant G^{-1}\left(1-a_{c}\right)$, viewers become active if $\omega_{1} \leqslant\left(1-\gamma\left(a_{c}+a_{e}\right)\right) / \lambda$, both politicians propose the median of the distribution function $H\left(x \mid a_{c}, a_{e}\right)$, uninfluenced voters split their votes equally between the two politicians, active advertisers propose an offer to trade $\left(\bar{\omega}_{2}, \bar{\omega}_{2}\right)$, and active viewers accept.

Proof. See the Appendix.

We can characterize equilibrium behavior by making use of the first-order conditions associated to the problem of the media firm described in Theorem 3.1(ii), since the maximand of the problem is log-concave. Let $\bar{a}_{c}$ be the unique solution to the problem

$$
\max _{0 \leqslant a_{c} \leqslant 1} \pi\left(a_{c}\right) \times F\left(\left(1-\gamma a_{c}\right) / \lambda\right)
$$


Intuitively, $\bar{a}_{c}$ is the target commercial advertisement for the media firm when the firm is unable or unwilling to sell political ads.

Similarly, let $\bar{a}_{e}$ be the unique solution to the problem

$$
\max _{a_{e}} a_{e} \times F\left(\left(1-\gamma a_{e}\right) / \lambda\right) .
$$

Intuitively, $\bar{a}_{e}$ is the optimal political advertisement for the media firm when the firm is unwilling to sell commercial ads, ignoring the constraint $a_{e}^{*} \leqslant 1 / \delta$. If $\bar{a}_{e}<$ $1 / \delta$, the media firm is willing to influence the voting behavior of only some active viewers, while if $\bar{a}_{e} \geqslant 1 / \delta$, the political influence of the media is strong enough for the media firm to be willing to influence the voting behavior of all active viewers.

To avoid dealing with corner solutions such that all viewers are active, we further impose

$$
\min \left\{\bar{a}_{c}, 1 / \delta\right\}>\left(1-\lambda \bar{\omega}_{1}\right) / \gamma
$$

Under assumption $\mathrm{C}, \bar{a}_{c}$ and $\bar{a}_{e}$ are interior solutions to the problems M' and M", respectively. It is easy to verify that

$$
0<\bar{a}_{c}<\bar{a}_{e}<\left(1-\lambda \underline{\omega}_{1}\right) / \gamma
$$

where the first inequality follows from the assumption that $\underline{\omega}_{1}<1 / \lambda$, the second inequality from $\pi^{\prime}\left(a_{c}\right)<1$ for $a_{c}>0$ and from the assumption that $\delta \leqslant 1$, and the third inequality follows from $F\left(\underline{\omega}_{1}\right)=0$.

We have ${ }^{4}$

Theorem 3.2. (i) If $\delta r \leqslant \bar{\omega}_{2} \pi^{\prime}\left(\bar{a}_{c}\right)$, then $a_{c}^{*}=\bar{a}_{c}$ and $a_{e}^{*}=0$. (ii) If $\bar{\omega}_{2} \pi^{\prime}\left(\bar{a}_{c}\right) \leqslant$ $\delta r \leqslant \bar{\omega}_{2}$, then $a_{c}^{*}$ and $a_{e}^{*}$ solve

$$
\bar{\omega}_{2} \pi^{\prime}\left(a_{c}\right)=\left(\bar{\omega}_{2} \pi\left(a_{c}\right)+\delta r a_{e}\right)(\gamma / \lambda) D \ln F\left(\left(1-\gamma\left(a_{c}+a_{e}\right)\right) / \lambda\right) \leqslant \delta r
$$

for $a_{e}^{*} \leqslant 1 / \delta$, with strict equality if $a_{e}^{*}<1 / \delta$. (iii) If $\delta r \geqslant \bar{\omega}_{2}$, then $a_{c}^{*}=0$ and $a_{e}^{*}=\min \left\{\bar{a}_{e}, 1 / \delta\right\}$.

Proof. The problem of the firm in Theorem 3.1 can be rewritten as:

$$
\max _{\substack{a_{c} \geqslant 0 \\ 0 \leqslant a_{e} \leqslant 1 / \delta}} \ln \left(\bar{\omega}_{2} \pi\left(a_{c}\right)+\delta r a_{e}\right)+\ln F\left(\left(1-\gamma\left(a_{c}+a_{e}\right)\right) / \lambda\right) .
$$

The Kuhn-Tucker conditions for the problem are

$$
\frac{\bar{\omega}_{2} \pi^{\prime}\left(a_{c}^{*}\right)}{\bar{\omega}_{2} \pi\left(a_{c}^{*}\right)+\delta r a_{e}^{*}} \leqslant(\gamma / \lambda) D \ln F\left(\left(1-\gamma\left(a_{c}^{*}+a_{e}^{*}\right)\right) / \lambda\right)
$$

\footnotetext{
${ }^{4}$ We use $D$ to denote the differential operator.
} 
with equality if $a_{c}^{*}>0$, and

$$
\begin{aligned}
& \frac{\delta r}{\bar{\omega}_{2} \pi\left(a_{c}^{*}\right)+\delta r a_{e}^{*}} \leqslant(\gamma / \lambda) D \ln F\left(\left(1-\gamma\left(a_{c}^{*}+a_{e}^{*}\right)\right) / \lambda\right) \quad \text { if } \quad a_{e}^{*} \geqslant 0, \\
& \frac{\delta r}{\bar{\omega}_{2} \pi\left(a_{c}^{*}\right)+\delta r a_{e}^{*}} \geqslant(\gamma / \lambda) D \ln F\left(\left(1-\gamma\left(a_{c}^{*}+a_{e}^{*}\right)\right) / \lambda\right) \quad \text { if } \quad a_{e}^{*} \leqslant 1 / \delta .
\end{aligned}
$$

Cases (i), (ii) and (iii) in the statement of the theorem correspond to the solutions to the system of equations (1)-(3) for the cases (i) $a_{c}^{*}>0, a_{e}^{*}=0$, (ii) $a_{c}^{*}>0, a_{e}^{*}>0$, and (iii) $a_{c}^{*}=0, a_{e}^{*}>0$. Note that $a_{c}^{*}=a_{e}^{*}=0$ cannot be a solution because then the firm would make zero profits, and the firm could make positive profits by increasing marginally either $a_{c}$ or $a_{e}$.

Assumption $\mathrm{C}$ allows a clean characterization of the firm's profit-maximizing decision in terms of marginal conditions, and implies that in equilibrium there are inactive viewers. For instance, if $1 / \delta<\min \left\{\bar{a}_{e},\left(1-\lambda \bar{\omega}_{1}\right) / \gamma\right\}$, so that assumption C fails, then for high enough political rents we have an "Orwellian" scenario, with all viewers being active and politically influenced by media. In this case, political advertising is given by $a_{e}=1 / \delta$, so as to influence all active viewers, and commercial advertisement given by the residual

$$
a_{c}=\left(1-\lambda \bar{\omega}_{1}\right) / \gamma-1 / \delta,
$$

so as to keep a full audience for the media firm.

Intuitively, in the Orwellian scenario, media's main objective is to keep control of the political behavior of all potential viewers, with commercial revenue being pursued only insofar it does not reduce the audience of the media. Complete irrelevance of viewers' actual policy interests is induced by the behavior of the media firm, even if the objective of the firm is solely maximizing profits.

\section{Comparative statics}

In this section we investigate the effects of varying political rents on the equilibrium behavior of the media and politicians. The effects on the behavior of politicians, in particular, highlight our main message that a media firm may have a big, unintentional impact on policy decisions as a by product of profit maximization.

We consider first the effects of political rents on equilibrium advertisement. From Theorem 3.2, political advertisement in zero if political rents are small, and completely crowds out commercial advertisement if political rents are high. For the intermediate case, when there is both commercial and political advertisement, we can show: 
Corollary 4.1. (i) If $a_{c}^{*}>0$ and $0<a_{e}^{*}<1 / \delta$, then a marginal increase in political rents strictly reduces commercial advertisement, strictly increases political advertisement, and strictly increases total advertisement. (ii) If $a_{c}^{*}>0$ and $a_{e}^{*}=1 / \delta$, then a marginal increase in political rents strictly reduces commercial advertisement and total advertisement.

Proof. Since from Theorem 3.1 the solution of the problem of the media firm is unique for any given value of political rents $r>0$, we can define with a slight abuse of notation $a_{c}(r), a_{e}(r)$, and $a(r)$ to be, respectively, the equilibrium commercial advertisement, electoral advertisement, and total advertisement, as a function of $r$. We are interested in changes in these variables in response to changes in $r$.

Let the initial value of political rents be $r^{\prime}$, and suppose first that $a_{c}\left(r^{\prime}\right)>0$ and $0<a_{e}\left(r^{\prime}\right)<1 / \delta$. From Theorem 3.2(ii), for $r$ in a neighborhood of $r^{\prime}$,

$$
\begin{aligned}
\delta r & =\bar{\omega}_{2} \pi^{\prime}\left(a_{c}(r)\right), \\
\frac{\bar{\omega}_{2} \pi\left(a_{c}(r)\right)-\delta r a_{c}(r)}{\delta r} & =\frac{1}{(\gamma / \delta) D \ln F((1-\gamma a(r)) / \lambda)}-a(r) .
\end{aligned}
$$

Note that $a_{c}(r)$ is given implicitly by equation (4) near $r^{\prime}$. Since $\pi$ is strictly concave, from equation (4) it follows that $a_{c}(r)$ is a decreasing, continuous and differentiable function.

Similarly, $a(r)$ is defined implicitly by equation (5) and $a_{c}(r)$ near $r^{\prime}$. We claim that the expression in the left-hand side of equation (5) strictly decreases with $r$. To see this, differentiating the denominator of this expression with respect to $r$ we get $\left(\bar{\omega}_{2} \pi^{\prime}\left(a_{c}\right)-\delta r\right) a_{c}^{\prime}(r)-\delta a_{c}(r)$; the claim follows from using equation (4). Since the expression in the right-hand side of equation (5) is strictly decreasing in $a(r)$, for equation (5) to hold, $a(r)$ must be strictly increasing. Since $a_{c}(r)$ is strictly decreasing, and $a(r)$ is strictly increasing, $a_{e}(r)$ must be strictly increasing.

Now suppose that $a_{c}\left(r^{\prime}\right)>0$ and $a_{e}\left(r^{\prime}\right)=1 / \delta$. From Theorem 3.2(ii), $a_{e}(r)$ remains constant after an increase in $r$. Hence,

$$
\frac{\bar{\omega}_{2} \pi^{\prime}\left(a_{c}(r)\right)}{\bar{\omega}_{2} \pi\left(a_{c}(r)\right)+r}=(\gamma / \lambda) D \ln F\left(\left(1-\gamma\left(a_{c}(r)+1 / \delta\right)\right) / \lambda\right)
$$

Note that $a_{c}(r)$ is given implicitly by equation (6). From concavity of $\pi$ and $\log$ concavity of $F$, it is simple to verify that an increase in $r$ reduces $a_{c}$.

In case (i) of Corollary 4.1, both political and commercial advertisement are interior solutions, and an increase in political rents increases the price of political advertisement and thus leads the firm to provide more political and less commercial advertisement. In case (ii), political advertisement is at an upper bound, influencing all active viewers to vote for the winner of the auction of political space, but 
the firm can increase the price of political advertisement by reducing commercial advertisement and thus increase the mass of active viewers.

Next we turn to the effect of political rents on politicians' behavior. It turns out that the incentives for politicians regarding which policy to propose are shaped by the mass of viewers who are influenced by the media, that is

$$
V \delta a_{e}^{*} F\left(\left(1-\gamma\left(a_{c}^{*}+a_{e}^{*}\right)\right) / \lambda\right) .
$$

From Theorem 3.2, the mass of influenced viewers remains constant after changes in political rents if they are so low that there is no political advertisement, or so high that there is no commercial advertisement. In the intermediate case have:

Corollary 4.2. If $a_{c}^{*}>0$ and $a_{e}^{*}>0$, a marginal increase in political rents strictly increases the mass of influenced viewers.

Proof. Along the lines of the proof of Corollary 4.1(i), we have that the equilibrium choices of political and total advertisement written as functions of the political rents, $a_{e}(r)$ and $a(r)$, are strictly increasing and differentiable.

Let the initial value of political rents be $r^{\prime}$, and suppose first that $a_{c}\left(r^{\prime}\right)>0$ and $0<a_{e}\left(r^{\prime}\right)<1 / \delta$. Differentiating the expression for the mass of viewers who are influenced by the media with respect to $r$, and rearranging terms, we get that the mass of influenced viewers increases after a marginal increase in $r$ if

$$
a_{e}^{\prime}(r) / a^{\prime}(r)>(\gamma / \delta) D \ln F\left(\left(1-\gamma\left(a_{c}^{*}+a_{e}^{*}\right)\right) / \lambda\right) a_{e}(r) .
$$

The left-hand side of this inequality is larger than one because political advertisement is increasing but commercial advertisement is decreasing in $r$, even if total advertisement is increasing. With respect to the right hand side, using equation (5) we have

$$
(\gamma / \delta) D \ln F((1-\gamma a(r)) / \lambda) a_{e}(r)=\frac{\delta r a_{e}(r)}{\bar{\omega}_{2} \pi\left(a_{c}(r)\right)+\delta r a_{e}(r)}<1
$$

Now suppose $a_{c}\left(r^{\prime}\right)>0$ and $a_{e}\left(r^{\prime}\right)=1 / \delta$. From Corollary 4.1(ii), $a_{e}(r)$ remains constant and $a(r)$ is reduced after a small increase in $r$, so the mass of influenced viewers increases.

Last, we consider the effect of political rents on the location of the median of $H\left(x \mid a_{c}^{*}, a_{e}^{*}\right)$, that is the policy proposed by the two candidates in equilibrium. As in previous cases, we need to consider only the intermediate case in who there is both political and commercial advertisement. We refer as the effective median voter to the type of viewer or advertiser whose ideal point is equal to the median of $H\left(x \mid a_{c}^{*}, a_{e}^{*}\right)$. We have: 
Corollary 4.3. If $a_{c}^{*}>0$ and $a_{e}^{*}>0$ and the effective median voter is a viewer, $a$ marginal increase in political rents strictly reduces the equilibrium policy choice.

Proof. See the Appendix.

For very low political rents there is no political advertisement, so that the effective median voter is necessarily a viewer and is given by $\tilde{x}$ satisfying $V F\left(X^{-1}(\tilde{x})\right)=$ $1 / 2$. That is, without political advertising the effective median voter and the median citizen coincide. Corollary 4.3 implies that further increases in political rents strictly reduce the policy adopted by politicians at least until the point that that the effective median voter is no longer a viewer, that is until the point that the policy adopted is larger than or equal to $X\left(\bar{\omega}_{1}\right)$. Increases in political rents beyond that point may have non monotonic effects on policy. The reason is that increasing political rents not only reduces the fraction of active viewers who are uninfluenced, whose ideal policies are in the right tail of the distribution, but also reduces the fraction of advertisers who are active, whose ideal policies are in the left tail of the distribution. In particular, for small enough commercial advertising, the policy adopted is bounded above by $X\left(\bar{\omega}_{1}\right)$.

Intuitively, media's political peddling affects voting behavior through two different channels: it makes viewers' vote in ways that are not related to their interests, which favors lower policy decisions, but it also make commercial advertisers poorer, which favors higher policy decisions. When the effective median voter is a viewer (not necessarily an active one), the first channel predominates.

\section{Optimal regulation and welfare}

We investigate in this section the implications of the firm's decision regarding advertising for social welfare from a simple utilitarian perspective. That is, for every possible decision $p, a_{e}$ for the firm, we measure social welfare as the sum of the payoffs to all the agents over the equilibrium path for the ensuing subgame, and we call a media decision socially optimal if it maximizes social welfare. As in previous sections, it is convenient to describe social welfare for every possible decision of the firm in terms of the target levels of commercial and political advertising, $a_{c}$ and $a_{e}$, so that the price for commercial advertising is given implicitly by $p=P\left(a_{c}, a_{e}\right)$.

Let $x^{m}\left(a_{c}, a_{e}\right)$ be the median of $H\left(x \mid a_{c}, a_{e}\right)$. Using Theorem 3.1(iii), social 
welfare can be written as

$$
\begin{aligned}
& V \int_{\omega_{1} \leqslant(1-\gamma a) / \lambda}\left[\omega_{1}-\left|x^{m}\left(a_{c}, a_{e}\right)-X\left(\omega_{1}\right)\right|+\left(1-\lambda \omega_{1}-\gamma a\right)\right] F\left(d \omega_{1}\right) \\
& +V \int_{\omega_{1}>(1-\gamma a) / \lambda}\left[\omega_{1}-\left|x^{m}\left(a_{c}, a_{e}\right)-X\left(\omega_{1}\right)\right|\right] F\left(d \omega_{1}\right) \\
& +(1-V) \int_{\sigma<G^{-1}\left(1-a_{c}\right)}\left[\bar{\omega}_{1}-\left|x^{m}\left(a_{c}, a_{e}\right)-X\left(\bar{\omega}_{1}\right)\right|\right] G(d \sigma) \\
& +(1-V) \int_{\sigma \geqslant G^{-1}\left(1-a_{c}\right)}\left[\bar{\omega}_{1}+\bar{\omega}_{2} \sigma F((1-\gamma a) / \lambda)-P\left(a_{c}, a_{e}\right)\right. \\
& \left.-\left|x^{m}\left(a_{c}, a_{e}\right)-X\left(\bar{\omega}_{1}+\bar{\omega}_{2} \sigma F((1-\gamma a) / \lambda)\right)\right|\right] G(d \sigma) \\
& +P\left(a_{c}, a_{e}\right) a_{c}+\delta r F((1-\gamma a) / \lambda) \\
& +r-\delta r F((1-\gamma a) / \lambda) .
\end{aligned}
$$

The first four summands in the expression above are, from top to bottom, the aggregate payoffs to active viewers, inactive viewers, inactive advertisers, and active advertisers, the fifth term is the media firm's revenue, and the sixth term is the sum of the two politicians' payoffs.

Collecting terms, social welfare is equal to

$$
\begin{gathered}
W\left(a_{c}, a_{e}\right) \equiv \\
V \int_{\omega_{1} \leqslant(1-\gamma a) / \lambda}\left(1-\lambda \omega_{1}-\gamma a\right) F\left(d \omega_{1}\right) \\
+(1-V) \int_{\sigma \geqslant G^{-1}\left(1-a_{c}\right)} \bar{\omega}_{2} F((1-\gamma a) / \lambda) \sigma G(d \sigma) \\
-\left[V \int_{\omega_{1}}\left|x^{m}\left(a_{c}, a_{e}\right)-X\left(\omega_{1}\right)\right| F\left(d \omega_{1}\right)+(1-V)\left(1-a_{c}\right)\left|x^{m}\left(a_{c}, a_{e}\right)-X\left(\bar{\omega}_{1}\right)\right|\right. \\
\left.+(1-V) \int_{\sigma \geqslant G^{-1}\left(1-a_{c}\right)}\left|x^{m}\left(a_{c}, a_{e}\right)-X\left(\bar{\omega}_{1}+\bar{\omega}_{2} \sigma F((1-\gamma a) / \lambda)\right)\right| G(d \sigma)\right]
\end{gathered}
$$

plus a term that is constant in $a_{c}$ and $a_{e}$. The first summand in the definition of $W\left(a_{c}, a_{e}\right)$ represents the entertainment value of media, the second summand represents the commercial value of media, and the third term represents the political impact of media.

We first investigate the effect of varying political rents on social welfare if the firm adopts the profit-maximizing decision. From Corollary 4.1, if $a^{*}>0$ and $0<a_{e}^{*}<1 / \delta$, increasing political rents increases total advertising, which affects adversely the entertainment and the commercial value of media, and reduces commercial advertising, which affects adversely commercial advertising. From Corollary 4.3 , if $a^{*}>0,0<a_{e}^{*}$, and the median voter is a viewer, a marginal increase 
in political rents reduces the equilibrium political choice. While the ideal policy of the effective median voter, $x^{m}\left(a_{c}, a_{e}\right)$, is influenced by advertising, the ideal policy of the median citizen is $\tilde{x}$ satisfying $V F\left(X^{-1}(\tilde{x})\right)=1 / 2$ regardless of advertising; by reducing the equilibrium political choice, larger political rents affect adversely the policy component of social welfare. It is immediate

Corollary 5.1. If $a^{*}>0,0<a_{e}^{*}<1 / \delta$, and the median voter is a viewer, a marginal increase in political rents makes society strictly worse off.

The effect of larger political rents if $a_{e}^{*}=1 / \delta$ in ambiguous. Intuitively, larger political rents reduce commercial advertising, which affects negatively the commercial value of media, but also reduce total advertising, which increases the entertainment value.

Next, we ask about the socially optimal decision about political and commercial advertising. This is the decision that would be adopted by a simple utilitarian regulator who can control directly the decision of the firm, but cannot control directly the decisions of other agents. For every $a_{c}$, we have $x^{m}\left(a_{c}, 0\right)=\tilde{x}$, so the ideal median policy is attained by shutting down political advertising. Since preferences are Euclidian, setting $a_{e}$ equal to zero, then, maximizes the policy component of $W\left(a_{c}, a_{e}\right)$ for any level of $a_{c}$. The other two components are strictly decreasing in political advertising. The following is immediate:

Corollary 5.2. The socially optimal level of political advertising is zero.

The socially optimal level of commercial advertising is given by

$$
\begin{aligned}
a_{c}^{0} \in \arg \max _{a_{c}} W\left(a_{c}, 0\right)= & \arg \max _{a_{c}}\left\{V \int_{\omega_{1} \leqslant\left(1-\gamma a_{c}\right) / \lambda}\left(1-\lambda \omega_{1}-\gamma a_{c}\right) F\left(d \omega_{1}\right)\right. \\
& \left.+(1-V) \int_{\sigma \geqslant G^{-1}\left(1-a_{c}\right)} \bar{\omega}_{2} \sigma F\left(\left(1-\gamma a_{c}\right) / \lambda\right) G(d \sigma)\right\} .
\end{aligned}
$$

Note that the social problem is quite different than the profit-maximization problem of the firm even if, say, political advertising is undesirable for the firm, as in problem (M') in Section 3. In particular, profit-maximization by the firm ignores the effect $a_{c}$ on intramarginal viewers and advertisers. The parameter $\bar{\omega}_{2}$ plays no role in the profit-maximization problem, while it provides the relative weight between viewers' welfare and commercial value in the social problem. As a consequence, and in consonance with Anderson and Coate (2005), there may be under or over provision of advertising under profit maximization; that is, both $a_{c}^{0}>\bar{a}_{c}$ and $a_{c}^{0}<\bar{a}_{c}$ are possible. 
Assuming that the regulator can affect the commercial decisions of the firm may be unrealistic and possible undesirable under many circumstances, for instance because the regulator itself may be politically motivated. We may ask if society is better off by shutting down political advertising and letting the firm choose commercial advertising to maximize profits, than if the firm chooses freely both commercial and political advertising. The viewpoint here is that of a simple utilitarian regulator that can only affect politically related activities or connections of the media firm, but cannot influence directly the firm's purely commercial operations. In the absence of political advertising, the firm's decision regarding commercial advertising is given by $\bar{a}_{c}$ as defined in Section 3. From Theorem 3.2, this is the value of commercial and total advertising if political rents are low enough. Moreover, in the absence of political advertising, the policy is given by $\tilde{x}$. Further increases in political rents reduce the entertainment value and the commercial value of the media if $0<a_{e}^{*}<1 / \delta$, and cannot lead to a better policy than without political advertising. We have:

Corollary 5.3. If $0<a_{e}^{*}<1 / \delta$, society is strictly better off if political advertising is forbidden.

If $a_{e}^{*}=1 / \delta$, that is, if the political behavior of active viewers is completely determined by the media, the effect on social welfare of forbidding political advertising is ambiguous. Suppose $\delta r>\bar{\omega}_{2}$ and $1 / \delta \leqslant \bar{a}_{e}$; from Theorem 3.2, this implies that in the initial situation we have $a_{c}^{*}=0$ and $a_{e}^{*}=1 / \delta$. By forbidding political advertising, political advertising is lead to zero and commercial advertising to $\bar{a}_{c}$. The loss in the entertainment value of the media by forbidding political advertising is positive if $1 / \delta<\bar{a}_{c}$. The gain in the commercial value of media is linear in $\bar{\omega}_{2}$ and moreover can be made arbitrarily small by setting $\bar{\omega}_{2}$ close to zero, which does not affect $\bar{a}_{c}$. The gain in policy in going from $X\left(\bar{\omega}_{1}\right)$ in the initial situation to the ideal median policy can be made arbitrarily small by setting $\beta$ close to zero.

To illustrate the argument in the previous paragraph, suppose $\gamma=\lambda=1 / 2$, $\delta=4, \omega_{1}$ distributed uniformly on $(1,2)$ and $\sigma$ distributed uniformly on $(0,1)$. We can calculate $\bar{a}_{c}=1 / 3$, so that, if political peddling is forbidden, the entertainment value of media is $V / 9$, the commercial value is $\bar{\omega}_{2}(1-V)(5 / 27)$, and the policy chosen is the ideal policy of the median citizen, that is $\alpha-\beta / 2 V$. If, instead, political peddling is allowed, and $4 r>\bar{\omega}_{2}$, the entertainment value of media is $9 \mathrm{~V} / 64$, the commercial value is zero, and the policy chosen is bounded above by $\alpha-2 \beta$, since all advertisers are inactive. An upper bound on the political loss is $V \times \beta(2-1 / 2 V)=\beta(2 V-1 / 2)$. Thus, society is made worse off by forbidding political peddling if

$$
9 V / 64-V / 9-\bar{\omega}_{2}(1-V)(5 / 27)-\beta(2 V-1 / 2),
$$


which holds if $\bar{\omega}_{2}$ and $\beta$ are small enough. Thus,

Corollary 5.4. If $a_{e}^{*}=1 / \delta$, society may be worse off if political advertising is forbidden.

Intuitively, if the influence of advertising on voting behavior is very strong, citizens preferences about policy are fairly homogeneous, and commercial advertising is not very valuable, society may be better served by politicians subsidizing viewers, even if this shuts down the commercial value of media and creates political distortions.

\section{Final remarks}

We have developed a tractable model of a dominant broadcast media firm, illustrating the conflict between the different objectives of the firm from a profitmaximizing perspective-namely revenue from commercial advertising and rent extraction from political influence. We use the model to decompose the effect of media decisions on social welfare into its three components, namely entertainment value for viewers, commercial value for advertisers, and changes in the electoral equilibrium affecting all citizens. We show that, under general circumstances, political rent extraction by the media has deleterious effects on social welfare, and discuss extraordinary circumstances under which this conclusion does not hold.

We have left several important topics for further work. One such is the programming decisions of the media firm. Programming may shape the viewership, and rent extraction and commercial revenue may point on different directions in terms of the targeted audience for the media. In particular, rent extraction may point in the direction of maximizing electoral impact, which should favor a larger, presumably poorer audience, while commercial revenue may favor catering to relatively more affluent citizens. Of course, one way through which media conglomerates attend to different audiences is by offering different channels; one insight form a political economic perspective is that such diversified offer may respond not only to purely commercial decisions. Another important topic we have left out is competition between several media firms. Competition and collusion among platforms are challenging topics and the object of attention of ongoing research in industrial organization.

The study of media conglomerates from both an industrial organization and a political perspective is, we believe, an exciting area of research and one that can bring both about a better understanding of the economic and political role of media conglomerates in the working of modern democracies and a firmer basis for regulatory design. 


\section{Appendix}

\section{Proof of Theorem 3.1}

To investigate equilibrium behavior, we proceed backwards from the last stages of the game. For any history at the trading stage and for any quality an active advertiser, the subgame played in the last two stages between an active advertiser and an active viewer who have been matched is a familiar ultimatum bargaining game. In the unique subgame perfect equilibrium path of this ultimatum game, (under assumption A) active advertisers propose an offer to trade $\left(\bar{\omega}_{2}, \bar{\omega}_{2}\right)$, and active viewers accept.

Given equilibrium behavior at the last two stages, viewers can anticipate a consumption level equal to their initial endowment of good 1 , that is $c_{1}+c_{2}=\omega_{1}$, regardless of whether they are active or inactive. Similarly, inactive advertisers can anticipate a consumption level equal to their initial endowment of good 1, that is $c_{1}=\bar{\omega}_{1}$. Active advertisers' consumption depends on whether they meet or not a viewer at the trading stage. If they meet a viewer, which happens with probability $\sigma v$, they obtain a consumption level of $\bar{\omega}_{1}+\bar{\omega}_{2}-p$. If they do not meet a viewer, which happens with probability $1-\sigma v$, they obtain a consumption level of $\bar{\omega}_{1}-p$. Thus, the expected consumption of active viewers is $\bar{\omega}_{1}+\sigma v \bar{\omega}_{2}-p$.

Given their expected consumption levels, at the voting stage the ideal levels of the public good for viewers are given by $X\left(\omega_{1}\right)$. Similarly, the ideal levels of the public good for inactive and active advertisers are, respectively, $X\left(\bar{\omega}_{1}\right)$ and $X\left(\bar{\omega}_{1}+\sigma v \bar{\omega}_{2}-p_{c}\right)$. Given their Euclidian preferences over levels of the public good, in any political economic equilibrium uninfluenced citizens at the voting stage vote for the politician whose proposal is closer to their ideal public good level, splitting their votes exactly in case of indifference, while influenced viewers vote for the winner of the political auction.

At the electoral competition stage, the bid paid by the winner of the political auction is already a sunk cost, so that both politicians seek to maximize their vote shares. Moreover, since influenced voters' behavior is predetermined by the result of the political auction, both politicians seek to maximize their votes among uninfluenced voters. It is simple to check that in equilibrium both politicians offer policies that are medians of the ideal levels of the public good among uninfluenced citizens. This is because, if any politician expects to obtain less than half the votes, the by mimicking the policy choice of the other politician can obtain half the votes. In particular, if the median is unique, politicians offer the same policy.

At the watching stage, viewers' optimal behavior and correct expectations about their consumption levels imply that in equilibrium, for any previous history, 
they watch the media if and only ${ }^{5}$ if $1-\lambda \omega_{1}-\gamma a \geqslant 0$ or equivalently if and only if

$$
\omega_{1} \leqslant \frac{1-\gamma a}{\lambda}=\frac{1-\gamma\left(a_{c}+a_{e}\right)}{\lambda}
$$

The equilibrium fraction of active viewers, then, for any history at the watching stage is given by

$$
F\left(\left(1-\gamma\left(a_{c}+a_{e}\right)\right) / \lambda\right) .
$$

At the ad market stage, advertisers' optimal behavior and correct expectations about decisions of other advertisers and future decisions of viewers imply that in equilibrium, for any choice of $a_{e}$ and $p$ by the firm, an advertiser becomes active if

$$
F\left(\left(1-\gamma\left(a_{c}+a_{e}\right)\right) / \lambda\right) \sigma \bar{\omega}_{2}-p \geqslant 0,
$$

or equivalently if

$$
\sigma \geqslant \frac{p}{\bar{\omega}_{2} F\left(\left(1-\gamma\left(a_{c}+a_{e}\right)\right) / \lambda\right)} .
$$

Thus, the equilibrium fraction of active advertisers is given by the solution to

$$
a_{c}=1-G\left(\frac{p}{\bar{\omega}_{2} F\left(\left(1-\gamma\left(a_{c}+a_{e}\right)\right) / \lambda\right)}\right) .
$$

For $a_{c}>0$, we can rewrite this expression as

$$
p=\bar{\omega}_{2} G^{-1}\left(1-a_{c}\right) F\left(\left(1-\gamma\left(a_{c}+a_{e}\right)\right) / \lambda\right)=P\left(a_{c}, a_{e}\right) .
$$

Note that for every $0 \leqslant a_{e}<\left(1-\lambda \underline{\omega}_{1}\right) / \gamma$ and every $0<p \leqslant \bar{\omega}_{2} F\left(\left(1-\gamma a_{e}\right) / \lambda\right)$, there is a unique solution $a_{c} \in\left[0,\left(1-\lambda \underline{\omega}_{1}\right) / \gamma-a_{e}\right)$ to equation (7); that is the level of commercial advertising in the unique equilibrium of the subgame following the firm's decision $\left(p, a_{e}\right)$. If the firm sets $p=0$, all advertisers become active in the ensuing subgame, since they are at least indifferent between buying an ad or not. If the firm sets instead $p \geqslant \bar{\omega}_{2} F\left(\left(1-\gamma a_{e}\right) / \lambda\right)$, the level of commercial advertising in the ensuing subgame is zero.

At the ad market stage as well, equilibrium behavior in the auction and correct expectations about decisions of advertisers and future decisions of viewers imply that politicians bid

$$
b_{1}=b_{2}=r \min \left\{\delta a_{e}, 1\right\} F\left(\left(1-\gamma\left(a_{c}+a_{e}\right)\right) / \lambda\right)
$$

\footnotetext{
${ }^{5}$ For simplicity, we have viewers and advertisers becoming active whenever they are indifferent. This is without loss of generality, since on the equilibrium path the sets of indifferent viewers and advertisers are zero measure.
} 
(This is the value of winning the political auction, when politicians anticipate correctly that regardless of who wins the political auction, they will split equally the votes of non influenced citizens.)

It is easy to see that $p=0$ cannot be revenue-maximizing. Similarly, choosing any price $\left.p>\omega_{2} F\left(\left(1-\gamma a_{e}\right)\right) / \lambda\right)$ is revenue equivalent to setting $p=\omega_{2} F((1-$ $\left.\left.\gamma a_{e}\right)\right) / \lambda$ ). Thus, we can write the problem of the firm as choosing both political and commercial advertising under the constraint

$$
a_{c}+a_{e} \leqslant\left(1-\lambda \underline{\omega}_{1}\right) / \gamma .
$$

Since increasing $a_{e}$ is detrimental for the firm for $a_{e} \geqslant 1 / \delta$, we can further restrict our attention to

$$
a_{e} \leqslant 1 / \delta \text {. }
$$

Given the choices of advertisers and viewers along the equilibrium path in the subgame following a firm's choice of $a_{e}$ and $p$, it is tedious but straightforward to verify that the distribution of ideal levels of the public good for non influenced voters is given by $H\left(a_{c}, a_{e}\right)$ if $p=P\left(a_{c}, a_{e}\right)$.

Using equations (7) and (8) and the objective of the firm, the profit maximization problem for the firm, then, can be written as

$$
\max _{a_{c}, a_{e}}\left\{\left(\bar{\omega}_{2} \pi\left(a_{c}\right)+\delta r a_{e}\right) \times F\left(\left(1-\gamma\left(a_{c}+a_{e}\right)\right) / \lambda\right)\right\}
$$

subject to

$$
0 \leqslant a_{c} \leqslant 1, \quad 0 \leqslant a_{e} \leqslant 1 / \delta \quad \text { and } \quad a_{c}+a_{e} \leqslant\left(1-\lambda \underline{\omega}_{1}\right) / \gamma .
$$

Since the expression for the objective of the firm in (M) is continuous and differentiable, and the choice set for $a_{c}$ and $a_{e}$ is compact, a solution for the problem of the firm exists and moreover it satisfies the usual first order conditions.

To show that the solution to problem $\mathrm{M}$ is unique, observe that, by assumption $\mathrm{B}, \omega_{2} \pi\left(a_{c}\right)+\delta r a_{e}$ is a concave function of $a_{c}$ and $a_{e}$, which in turn implies that it is also a log-concave function of $a_{c}$ and $a_{e}$. Similarly, since $F$ is log-concave, $F\left(\left(1-\gamma\left(a_{c}+a_{e}\right)\right) / \lambda\right)$ is a log-concave function of $a_{c}$ and $a_{e}$. Since the product of log-concave functions is log-concave, it follows that the objective function in problem $\mathrm{M}$ is log-concave as well, and therefore it has a unique maximum. To check that $a_{c}+a_{e} \leqslant\left(1-\lambda \underline{\omega}_{1}\right) / \gamma$ is never binding, note that if that inequality is not strict, the value of the objective function is zero, but the firm can make positive profits by setting $a_{e}$ and $a_{c}$ close enough to zero, since by assumption $\underline{\omega}_{1}<\lambda$. Similarly, $a_{c} \leqslant 1$ is never binding, since the value of the objective function in $\mathrm{M}$ can be increased by reducing $a_{c}$ and increasing $a_{e}$ pari passu whenever $a_{c}=1$, given that $\pi^{\prime}(1)<0$ but $\delta r>0$. Thus, the problem of the firm can be formulated 
as in part (ii) of the theorem, and it has a unique solution. The remainder of the equilibrium path can be obtained retracing our steps and it is as described by part (iii) of the theorem. In particular, substituting $P\left(a_{c}^{*}, a_{e}^{*}\right)$ for $p$ in the ideal points of voters we obtain that the distribution of ideal points is given by $H\left(x \mid a_{c}^{*}, a_{e}^{*}\right)$. By construction, the equilibrium path is unique, as required by part (i) of the theorem.

\section{Proof of Corollary 4.3}

For any pair $x^{\prime}, x^{\prime \prime} \in \mathfrak{R}$ such that $x^{\prime}<x^{\prime \prime}$, let

$$
m\left(r \mid x^{\prime}, x^{\prime \prime}\right) \equiv\left(H\left(x^{\prime \prime} \mid a_{c}(r), a_{e}(r)\right)-H\left(x^{\prime} \mid a_{c}(r), a_{e}(r)\right)\right) C\left(a_{c}(r), a_{e}(r)\right),
$$

and for any $x^{\prime} \in \Re$ let

$$
\begin{aligned}
m\left(r \mid-\infty, x^{\prime}\right) & \equiv\left(H\left(x^{\prime} \mid a_{c}(r), a_{e}(r)\right) C\left(a_{c}(r), a_{e}(r)\right),\right. \\
m\left(r \mid x^{\prime},+\infty\right) & \equiv\left(1-H\left(x^{\prime} \mid a_{c}(r), a_{e}(r)\right)\right) C\left(a_{c}(r), a_{e}(r)\right),
\end{aligned}
$$

where $a_{c}(r)$ and $a_{e}(r)$ are the equilibrium choices of commercial and political advertisement as a function of $r$. Intuitively, $m\left(r \mid x^{\prime}, x^{\prime \prime}\right)$ is the measure of the set of uninfluenced voters with ideal points in the interval $\left(x^{\prime}, x^{\prime \prime}\right]$, given that the level of political rents is $r$. Similarly, $m\left(r \mid-\infty, x^{\prime \prime}\right)$ and $m\left(r \mid x^{\prime},+\infty\right)$ are the measure of the sets of uninfluenced voters with ideal points respectively weakly below and strictly above $x^{\prime}$.

Let $x(r)$ denote the median of $H\left(x \mid a_{c}(r), a_{e}(r)\right)$, that is the equilibrium policy choice as a function of political rents. It is easy to see that, for any $r$ such that $x(r) \neq X\left(\bar{\omega}_{1}\right)$, we must have

$$
m\left(r \mid-\infty, x\left(r^{\prime}\right)\right)=m(r \mid x(r),+\infty)
$$

and moreover, $x>x(r)$ if and only if

$$
m(r \mid-\infty, x(r))>m(r \mid x(r),+\infty) .
$$

Now suppose that for the initial value of political rents $r^{\prime}$ we have $a_{c}\left(r^{\prime}\right)>0$, $a_{e}\left(r^{\prime}\right)>0$, and $X\left(\bar{\omega}_{1}\right)<x\left(r^{\prime}\right)<X\left(\left(1-\gamma a\left(r^{\prime}\right)\right) / \delta\right)$; that is, in the initial situation the median voter is an inactive viewer. If $r^{\prime \prime}>r^{\prime}$ is larger than but close enough to $r^{\prime}$, it must be that $X\left(\bar{\omega}_{1}\right)<x\left(r^{\prime \prime}\right)<X\left(\left(1-\gamma a\left(r^{\prime \prime}\right)\right) / \delta\right)$. Thus,

$$
m\left(r^{\prime \prime} \mid-\infty, x\left(r^{\prime}\right)\right)=m\left(r^{\prime} \mid-\infty, x\left(r^{\prime}\right)\right),
$$

because all citizens with ideal points above $x\left(r^{\prime}\right)$ are either advertisers, whose ideal points are bounded below by $X\left(\bar{\omega}_{1}\right)$, or inactive viewers, whose ideal points are 
unaffected by changes in advertising. However,

$$
\begin{aligned}
m\left(r^{\prime \prime} \mid x\left(r^{\prime}\right),+\infty\right) & =V F\left(X^{-1}\left(x\left(r^{\prime}\right)\right)\right)-V \delta a_{e}\left(r^{\prime \prime}\right) F\left(\left(1-\gamma a\left(r^{\prime \prime}\right)\right) / \lambda\right) \\
& >V F\left(X^{-1}\left(x\left(r^{\prime}\right)\right)\right)-V \delta a_{e}\left(r^{\prime}\right) F\left(\left(1-\gamma a\left(r^{\prime}\right)\right) / \lambda\right) \\
& =m\left(r^{\prime} \mid x\left(r^{\prime}\right),+\infty\right) .
\end{aligned}
$$

where the inequality in the second line follows from Corollary 4.2. Hence,

$$
m\left(r^{\prime \prime} \mid x\left(r^{\prime}\right),+\infty\right)<m\left(r^{\prime \prime} \mid-\infty, x\left(r^{\prime}\right)\right),
$$

so that $x\left(r^{\prime}\right)>x\left(r^{\prime \prime}\right)$.

Suppose instead that for the initial value of political rents $r^{\prime}$ we have $a_{c}\left(r^{\prime}\right)>$ $0, a_{e}\left(r^{\prime}\right)>0$, and $x\left(r^{\prime}\right)>X\left(\left(1-\gamma a\left(r^{\prime}\right)\right) / \delta\right)$; that is, in the initial situation the median uninfluenced voter is an active viewer. Note that this implies $a_{e}\left(r^{\prime}\right)<1 / \delta$; otherwise all the active viewers would be influenced. If $r^{\prime \prime}>r^{\prime}$ is larger than but close enough to $r^{\prime}$, it must be that $x\left(r^{\prime \prime}\right)>X\left(\left(1-\gamma a\left(r^{\prime \prime}\right)\right) / \delta\right)$. We can calculate

$$
m\left(r^{\prime \prime} \mid x\left(r^{\prime}\right),+\infty\right)=\frac{1-\delta r^{\prime \prime}}{1-\delta r^{\prime}} m\left(r^{\prime} \mid x\left(r^{\prime}\right),+\infty\right),
$$

because all voters with ideal points above $x\left(r^{\prime}\right)$ are active viewers, and the fraction of active viewers who are uninfluenced goes from $1-\delta r^{\prime}$ to $1-\delta r^{\prime \prime}$. From Corollary 4.1(i) we have $a\left(r^{\prime \prime}\right)>a\left(r^{\prime}\right)$ implying $\left.X\left(\left(1-\gamma a\left(r^{\prime \prime}\right)\right) / \delta\right)\right)>X((1-$ $\left.\left.\left.\gamma a\left(r^{\prime}\right)\right) / \delta\right)\right)$. Thus,

$$
\begin{aligned}
m\left(r^{\prime \prime} \mid-\infty, x\left(r^{\prime}\right)\right)= & m\left(r^{\prime \prime} \mid-\infty, X\left(\left(1-\gamma a\left(r^{\prime \prime}\right)\right) / \delta\right)\right) \\
& +m\left(r^{\prime \prime} \mid X\left(\left(1-\gamma a\left(r^{\prime}\right)\right) / \delta\right), X\left(\left(1-\gamma a\left(r^{\prime \prime}\right)\right) / \delta\right)\right) \\
& +m\left(r^{\prime \prime} \mid X\left(\left(1-\gamma a\left(r^{\prime \prime}\right)\right) / \delta\right), x\left(r^{\prime}\right)\right) \\
= & m\left(r^{\prime} \mid-\infty, X\left(\left(1-\gamma a\left(r^{\prime \prime}\right)\right) / \delta\right)\right) \\
& +\frac{1}{1-\delta r^{\prime}} m\left(r^{\prime} \mid X\left(\left(1-\gamma a\left(r^{\prime}\right)\right) / \delta\right), X\left(\left(1-\gamma a\left(r^{\prime \prime}\right)\right) / \delta\right)\right) \\
& +\frac{1-\delta r^{\prime \prime}}{1-\delta r^{\prime}} m\left(r^{\prime} \mid X\left(\left(1-\gamma a\left(r^{\prime \prime}\right)\right) / \delta\right), x\left(r^{\prime}\right)\right) \\
> & \frac{1-\delta r^{\prime \prime}}{1-\delta r^{\prime}} m\left(r^{\prime} \mid-\infty, x\left(r^{\prime}\right)\right) .
\end{aligned}
$$

Hence,

$$
m\left(r^{\prime \prime} \mid-\infty, x\left(r^{\prime}\right)\right)>m\left(r^{\prime \prime} \mid x\left(r^{\prime}\right),+\infty\right),
$$

so that $x\left(r^{\prime}\right)>x\left(r^{\prime \prime}\right)$. 


\section{References}

Anderson, S., Coate, S., 2005. Market provision of broadcasting: A welfare analysis. Review of Economic Studies 72 (4), 947-972.

Armstrong, M., 2006. Competition in two-sided markets. RAND Journal of Economics 37 (3), 668-691.

Bernhardt, D., Krasa, S., Polborn, M., 2008. Political polarization and the electoral effect of media bias. Journal of Public Economics 92, 1092-1104.

Besley, T., Prat, A., 2006. Handcuffs for the grabbing hand? Media capture and government accountability. American Economic Review 96 (3), 720-736.

DellaVigna, S., Kaplan, E., 2007. The Fox News effect: media bias and voting. Quarterly Journal of Economics 122 (3), 1187-1234.

Dooe, M., November 2013. Behind the data: TV viewing and income.

URL http://www.marketplace.org/topics/wealth-poverty/ income-upshot/behind-data-tv-viewing-and-income

Duggan, J., Martinelli, C., 2011. A spatial theory of media slant and voter choice. Review of Economic Studies 78 (2), 640-666.

Gentzkow, M., Shapiro, J., 2006. Media bias and reputation. Journal of Political Economy 114 (2), 280-316.

Gentzkow, M., Shapiro, J., 2015. Media bias in the marketplace: Theory. In: Anderson, S., Waldfogel, J., Stromberg, D. (Eds.), Handbook of Media Economics, Volume 1A. North Holland (forthcoming).

Gentzkow, M., Shapiro, J., Sinkinson, M., 2011. The effect of newspaper entry and exit on electoral politics. American Economic Review 101 (7), 2980-3018.

Groseclose, T., Milyo, J., 2005. A measure of media bias. Quarterly Journal of Economics 120 (4), 1191-1237.

IBOPE AGB, 2009. Anuario 2008 2009: Audiencias y medios en México.

Klein, E., 2015. Donald Trump's fight with Fox News and Megyn Kelly, explained. Vox Explainers, http://www.vox.com/2015/8/8/9121377/donald-trump-megynkelly. 
McCann, J. A., Lawson, C., 2005. Television news, Mexico's 2000 elections and media effects in emerging democracies. British Journal of Political Science 35 (1), 1-30.

Mcmillan, J., Zoido, P., 2004. How to subvert democracy: Montesinos in Peru. Journal of Economic Perspectives 18 (4), 69-92.

Mullainathan, S., Shleifer, A., 2005. The market for news. American Economic Review 95 (4), 1031-1053.

NORC, 2014. GSS General Social Survey.

URL http://wWw3.norc.org/GSS+Website/

Prat, A., 2014. Measuring media power, CEPR DP10094.

Prat, A., Stromberg, D., 2013. The political economy of mass media. In: Acemoglu, D., Arellano, M., Dekel, E. (Eds.), Advances in Economics and Econometrics, Tenth World Congress, Volume 2, Applied Economics. Cambridge University Press, pp. 135-187.

Rochet, J.-C., Tirole, J., 2003. Platform competition in two-sided markets. Journal of the European Economic Association 1 (4), 990-1029.

Telecom-CIDE, 2011. Condiciones del mercado de televisión abierta en México. Comisión Federal de Telecomunicaciones, Mexico.

Weyl, E. G., 2010. A price theory of multi-sided platforms. American Economic Review 100 (4), 1642-1672. 